\title{
Pengaruh Tanggapan Di Media Sosial Terhadap Pilihan Koleksi Bagi Pengunjung Interactive Art Museum Bali, Kota Denpasar
}

Gusti Ngurah Kade Wahyu Ari Hutama a, 1, I Gusti Agung Oka Mahagangga a, 2

1wahyuarihutama@gmail.com, 20kamahagangga@unud.ac.id

a Program Studi Sarjana Destinasi Pariwisata, Fakultas Pariwisata,Universitas Udayana, Jl. Dr. R. Goris, Denpasar, Bali 80232 Indonesia

\begin{abstract}
Interactive Art Museum Bali is the new one of tourists attraction in Denpasar City. Although classified as a new tourist attraction, but tourists visit the Interactive Art Museum Bali is always increasing every month. Based on that situation, the research is conducted for analyzing the influence of responses in social media on the collection options for visitors at the tourist attraction of Interactive Art Museum Bali, Denpasar City.

The data used in this research is quantitative data. Data analysis techniques used in this study are correlation analysis. The collected data in this study through observation, literature study, questionnaire, and visual material. Informant determination technique used is convenience sampling technique with the number of samples determined by the Slovin formula.

The results of this study obtained that the social media used by visitors who come to visit the Interactive Art Museum Bali is Instagram. The influence of responses in social media on collection options for visitors is seen from 3 classifications. First, according to the observing senses, has a correlation analysis of 0653 and 0.598 . The second classification is according to the occurrence of having correlation analysis results of 0.627 and 0.668 . The third characteristic is according to the environment has the result of correlation analysis of 0.564 and 0.585 .
\end{abstract}

Keywords: Social Media, Response, Visitor, Collection, Interactive Art Museum Bali

\section{PENDAHULUAN}

Pariwisata yang ada di Bali sudah mengalami perkembangan pariwisata yang sangat besar baik didalam kualitas ataupun kuantitas. Yang dapat dilihat dengan terus bertambahnya sarana dan prasarana penunjang pariwisata yaitu fasilitas pariwisata serta akomodasi. Hal inilah yang membuat keinginan pengunjung untuk mengunjungi pulau Bali.

Kota Denpasar merupakan kota yang selalu didatangi oleh pengunjung. Hal tersebut yang menjadikan Kota Denpasar sebagai inti perkembangan pariwisata yang sudah ada pada saat ini. Adapun destinasi pariwisata yang ada di Ibu Kota Provisi Bali ini antara lain Bajra Sandhi, Museum Bali serta Interactive Art Museum Bali.

Pada bulan Agustus 2016 Interactive Art Museum Bali (I AM Bali) mulai beroprasi. Dimana Interactive Art Museum merupakan salah satu museum di Kota Denpasar yang terdapat di pusat kota. Interactive Art Museum Bali tidak hanya memasarkan lukisan interaktif 3D tetapi memasarkan berbagai macam fasilitas serta arena bermain. Tema untuk lukisan pada Interactive Art Museum Bali memiliki nilai edukasi, kreatif serta interaktif dimana hal tersebut mampu memberi suatu nilai positif terhadap pengunjung.

Tingkat kunjungan pengunjung di Interactive Art Museum Bali yang selalu mengalami kenaikan angka setiap bulannya dimana terdapat juga penurunan angka pada kunjungan pengunjung. Media sosial merupakan faktor yang dapat mempengaruhi perilaku dari wisatawan dalam memutuskan perjalanan. Data kunjungan pengunjung dapat dilihat pada tabel 1 dibawah ini:

Tabel 1. Kunjungan Pengunjung Interactive Art Museum Bali tahun 2018

\begin{tabular}{cccc}
\hline Bulan & Kunjungan & Bulan & Kunjungan \\
\hline Januari & 4.625 & Juli & 4.749 \\
Februari & 2.530 & Agustus & 3.180 \\
Maret & 3.588 & September & 3.349 \\
April & 4.463 & Oktober & 3.425 \\
Mei & 3.324 & November & 3.612 \\
Juni & 6.385 & Desember & 7.496 \\
\hline \multicolumn{2}{c}{ Total } & \multicolumn{2}{c}{$\mathbf{5 0 . 7 2 6}$}
\end{tabular}

Sumber : Interactive Art Museum Bali, 2018

Perkembangan teknologi yang semakin pesat dan maju menjadikan Interactive Art Museum Bali mulai mudah diketahui oleh banyak wisatawan domestik maupun mancanegara. Sehingga wisatawan mulai datang berkunjung ke Interactive Art Museum Bali. Hal tersebut menjadikan tanggapan di 
media sosial memiliki pengaruh terhadap pilihan koleksi bagi pengunjung Interactive Art Museum Bali. Penelitian ini berfokus pada media sosial yang digunakan pengunjung dan pengaruh tanggapan di media sosial terhadap pilihan koleksi bagi pengunjung di daya tarik wisata Interactive Art Museum Bali.

\section{TINJAUAN PUSTAKA}

\subsection{Telaah Hasil Penelitian Sebelumnya}

Penelitian pertama yang dijadikan acuan adalah penelitian yang dilakukan oleh Lidia Uli Christiani Karmelia Hutagalung dan Saptono Nugroho (2015) dengan judul "Efektivitas Program City Tour Terhadap Peningkatan Jumlah Kunjungan Pengunjung di Museum Bali Denpasar". Di dalam penelitian ini menjelaskan mengenai besarnya efektivitas program Denpasar City Tour dalam penaikan angka kunjungan pengunjung di Museum Bali yang menunjukan angka yang cukup baik.

Penelitian selanjutnya yang menjadi acuan adalah penelitian yang dilakukan oleh Moch Hari Purwidiantoro, dkk (2016) dengan judul "Pengaruh Penggunaan Media Sosial Terhadap Pengembangan Usaha Kecil Menengah (UKM)". Penelitian ini menjelaskan tentang sebagian besar penggunaan media sosial bagi UKM adalah untuk komunikasi dengan konsumen, memberikan respon kepada konsumen serta pemasaran dan iklan.

Penelitian selanjutnya yang menjadi acuan adalah penelitian yang dilakukan oleh Ferry Marlianto, dkk (2016) dengan judul "Pengaruh Media Sosial Terhadap Kreativitas dan Kepribadian Mahasiswa Pendidikan TIK IKIP PGRI Pontianak". Penelitian ini menjelaskan tentang pengaruh dan signifikansi antara kreativitas terhadap media sosial Program Studi Pendidikan TIK IKIP PGRI.

\subsection{Deskripsi Konsep Analisis}

\section{PARIWISATA}

Pariwisata ialah suatu aktivitas perjalanan yang memiliki waktu kunjungan yang sementara waktu dari daerah asal ke daerah tujuan. Tidak untuk tinggal atau mendapatkan uang antara lain hanya untuk bersenang-senang serta untuk menghabiskan waktu senggang (Koen Meyers; 2010).

\section{PENGARUH}

Pengaruh merupakan kekuatan yang timbul dalam seseorang dengan gejala yang dapat memberikan efek perubahan terhadap apa yang ada di sekitarnya (Surakhmad; 1982).

\section{MEDIA SOSIAL}

Media sosial adalah salah satu sarana bagi seseorang untuk berbagi gambar, pesan, suara serta informasi baik antara perusahaan dengan konsumen atau konsumen dengan konsumen lainnya (Kotler; 2012). Media sosial terbagi menjadi tiga yaitu :

a. Komunitas dan Forum Online

Terbentuk oleh konsumen dan sekelompok konsumen yang tergabung dalam forum online serta mampu berkomunikasi dengan anggota lainnya.

b. Blog

Blog adalah suatu catatan online yang selalu dicari serta dipulihkan secara terus menerus dan juga merupakan suatu saluran yang sangat penting bagi word of mouth.

c. Jaringan Sosial

Jaringan sosial merupakan suatu alasan penting didalam melakukan pemasaran baik itu business to customer dan business to business. Jaringan sosial berupa situs jejaring sosial seperti Facebook, Instagram, Twitter, Path, Whatsapp dan lain-lain.

\section{TANGGAPAN}

Agus Sujanto (1996) mengklasifikasikan tanggapan ke dalam tiga bagian:

1. Menurut indera yang mengamati terdapat tanggapan auditif; tanggapan visual; tanggapan perasa.

2. Menurut terjadinya terdapat tanggapan ingatan; tanggapan fantasi; tanggapan fikir.

3. Menurut Lingkungannya terdapat tanggapan benda dan tanggapan perkataan.

\section{PENGUNJUNG}

Wisatawan adalah orang-orang yang datang berkunjung pada suatu tempat, yang dimana sering disebut sebagai pengunjung yang berisikan banyak orang dan dengan bermacam-macam motivasi kunjungan (Undang-undang No.10 tahun 2009).

\section{DAYA TARIK WISATA}

Daya tarik wisata ialah segala sesuatu yang terdapat didaerah tujuan wisata yang memiliki keunikan dan menjadi daya tarik agar orang 
mau berkunjung (Yoeti; 1997).

\section{KOMUNIKASI DIGITAL}

Suatu sistem komunikasi yang menggunakan urutan digital seperti antarmuka antara sumber dan input saluran dan juga antara keluaran saluran dan tujuan akhir (Gallager; 2008).

\section{LUKISAN 3 DIMENSI}

Lukisan 3 Dimensi atau Trimatra merupakan seni rupa yang memiliki volume atau isi dan memiliki tiga ukuran antara lain panjang, lebar, dan tinggi (Susanto; 2011).

\section{MUSEUM}

Museum merupakan sarana edukasi yang dapat dirasakan oleh setiap kalangan, hanya kadang kala konsep museum menjadi sedikit berubah seiring berjalannya waktu terutama dari tujuan awal museum yang seharusnya dapat memberikan makna pembelajaran bagi setiap orang yang berkunjung (Bruninghaus dan Knubel; 2004).

\section{METODE}

Penelitian ini dilakukan di Interactive Art Museum Bali yang terdapat di lantai dasar Monumen Perjuangan Rakyat Bali, Kota Denpasar. Ruang lingkup penelitian ini adalah media sosial yang digunakan pengunjung dan pengaruh tanggapan pengunjung di media sosial terhadap pilihan koleksi bagi pengunjung Interactive Art Museum Bali.

Jenis data dalam penelitian ini adalah data kuantitatif. Sementara itu, sumber data dalam penelitian ialah data sekunder dan data primer. Dan teknik pengumpulan data pada penelitian ini ialah studi kepustakaan, observasi, kuesioner serta materi visual.

Dan teknik pengambilan sampel pada penelitian ini ialah dengan menggunakan rumus Slovin serta dengan teknik pengambilan sampel yaitu convenience sampling (Audifax; 2008). Variabel yang terdapat di penelitian ini ialah variabel bebas dan variabel terikat.

Teknik analisis data yang digunakan pada penelitian ini ialah analisis korelasi, yaitu suatu metode untuk melihat adakah hubungan antara variabel (Sarwono; 2006).
IV. HASIL DAN PEMBAHASAN

4.1. Media Sosial yang Digunakan Pengunjung Interactive Art Museum Bali

\subsubsection{Karakteristik Pengunjung}

Berikut karakteristik pengunjung yang datang ke Interactive Art Museum Bali yaitu:

1. Berdasarkan Jenis Kelamin

Sebesar $41 \%$ pengunjung yang datang memiliki jenis kelamin laki-laki serta sebesar $59 \%$ pengunjung yang datang memiliki jenis kelamin perempuan. Hal itu disebabkan karena perempuan lebih menyukai kegiatan berfoto dibandingkan laki-laki.

2. Berdasarkan Asal

Pengunjung yang datang kebanyakan berasal dari luar bali dengan tingkat presentase sebesar $72 \%$ sedangkan pengunjung yang berasal dari bali memiliki tingkat presentase sebesar $28 \%$.

\subsubsection{Media sosial yang digunakan pengunjung}

Pengunjung yang berkunjung di Interactive Art Museum Bali memakai 3 akun media sosial. Didapatkan sebanyak 25 orang pengunjung yang berkunjung menggunakan jenis media sosial Facebook. Sedangkan 1 orang pengunjung yang berkunjung menggunakan jenis media sosial Twitter. Dan didapatkan sebanyak 37 orang pengunjung yang berkunjung menggunakan jenis media sosial Instagram.

Selain itu, didapatkan 2 orang pengunjung yang berkunjung menggunakan dua jenis media sosial yaitu Instagram dan Twitter. Sebanyak 1 orang pengunjung yang berkunjung menggunakan dua jenis media sosial yaitu Facebook dan Twitter. Sebanyak 29 orang pengunjung yang berkunjung menggunakan dua jenis media sosial yaitu Instagram dan Facebook. Sedangkan sebanyak 5 orang pengunjung yang berkunjung menggunakan tiga jenis media sosial yaitu Instagram, Facebook, dan Twitter.

\subsection{Pengaruh Tanggapan di Media Sosial terhadap Pilihan Koleksi Bagi Pengunjung Interactive Art Museum Bali \\ Pengaruh tanggapan dapat dilihat dari media sosial yang digunakan pengunjung yang datang serta sumber informasi yang didapatkan tentang Interactive Art Museum Bali. Didapatkan sebanyak 51 orang pengunjung yang datang mendapatkan informasi di media}


sosial. Waktu antara pengunjung mengetahui informasi tentang Interactive Art Museum Bali adalah 5 bulan yang lalu.

Sementara itu, tanggapan yang ada di media sosial memiliki pengaruh yang penting terhadap pilihan koleksi bagi pengunjung Interactive Art Museum Bali. Hal ini, dilihat berdasarkan 3 klasifikasi bagian konsep tanggapan sebagai berikut:

\section{Menurut Indera yang Mengamati}

Klasifikasi bagian ini dilihat berdasarkan tanggapan pengunjung mengenai apa yang menarik di Interactive Art Museum Bali. Didapatkan sebesar $3 \%$ pengunjung yang datang menyebutkan hal yang menarik dari Interactive Art Museum Bali ialah rumah hantu. Dan sebesar 8\% pengunjung yang datang menyebutkan hal yang menarik dari Interactive Art Museum Bali ialah upside down. Sedangkan sebesar $70 \%$ pengunjung yang datang menyebutkan hal yang menarik dari Interactive Art Museum Bali merupakan lukisan 3D.

Sementara itu, sebesar 8\% pengunjung yang datang menyebutkan hal yang menarik di Interactive Art Museum Bali ialah upside down serta lukisan 3D. Sebesar 7\% pengunjung yang berkunjung menyebutkan hal yang menarik di Interactive Art Museum Bali ialah rumah hantu serta upside down. Dan sebesar 4\% pengunjung yang datang menyebutkan hal yang menarik di Interactive Art Museum Bali ialah semua wahana yang ada.

Selain tentang yang menarik di Interactive Art Museum Bali, pengunjung juga memiliki tanggapan pengunjung mengenai yang dilakukan pengunjung di Interactive Art Museum Bali. Sebesar 69\% kegiatan pengunjung di Interactive Art Museum Bali ialah berfoto. Sebesar 4\% kegiatan pengunjung di Interactive Art Museum Bali ialah bercanda. Dan sebesar 8\% kegiatan pengunjung di Interactive Art Museum Bali ialah membeli dan makan ice cream.

Sementara itu, sebesar 5\% kegiatan pengunjung di Interactive Art Museum Bali ialah bercanda dan berfoto. Sebesar 12\% kegiatan pengunjung di Interactive Art Museum Bali ialah memakan ice cream dan berfoto. Dan sebesar 2\% kegiatan pengunjung di Interactive Art Museum Bali ialah bercanda, memakan ice cream dan berfoto.

Dari hasil penjabaran diatas, selanjutnya dilakukan analisis korelasi antara variabel. Hasil dari analisis korelasi dapat dilihat pada tabel 4.2 dibawah ini:

Tabel 4.2 Analisis Korelasi

\begin{tabular}{cc}
\hline Analisi Korelasi & Intagram \\
\hline Berfoto & 0,598 \\
\hline Lukisan 3D & 0,653 \\
\hline Sumber : Hasil Penelitian, 2018
\end{tabular}

Hasil analisis korelasi pada klasifikasi bagian ini menghasilkan angka 0,598 dan 0,653 . Hal tersebut menunjukan bahwa media sosial Instagram memiliki hubungan yang sangat kuat dengan lukisan 3D dan berfoto karena angka koefisien dari hasil analisis korelasi tersebut diatas nilai 0,5.

\section{Menurut Terjadinya}

Dari klasifikasi bagian berdasarkan tanggapan pengunjung mengenai apa yang diingat serta yang dipikirkan dari Interactive Art Museum Bali. Didapatkan sebesar 63\% pengunjung yang berkunjung menyebutkan hal yang diingatnya dari Interactive Art Museum Bali ialah lukisan 3D. Sebesar 10\% pengunjung yang berkunjung menyebutkan hal yang diingatnya dari Interactive Art Museum Bali ialah rumah hantu. Dan sebesar 14\% pengunjung yang berkunjung menyebutkan hal yang diingatnya dari Interactive Art Museum Bali ialah upside down.

Sementara itu, sebesar 5\% pengunjung yang berkunjung menyebutkan hal yang diingatnya dari Interactive Art Museum Bali ialah rumah hantu dan upside down. Sebesar $8 \%$ pengunjung yang berkunjung menyebutkan hal yang diingatnya dari Interactive Art Museum Bali ialah lukisan 3D dan upside down.

Selain mengenai yang diingat oleh pengunjung dari Interactive Art Museum Bali. Pengunjung juga memiliki tanggapan mengenai yang didapatkan pengunjung di Interactive Art Museum Bali. Sebesar 45\% pengunjung yang berkunjung mengatakan hal yang didapatkan di Interactive Art Museum Bali ialah foto. Sebesar $15 \%$ pengunjung yang berkunjung menyebutkan hal yang didapatkan di Interactive Art Museum Bali ialah pengetahuan. Dan Sebesar 21\% pengunjung yang berkunjung 
menyebutkan hal yang didapatkan di Interactive Art Museum Bali adalah pengalaman.

Sementara itu, sebesar $2 \%$ pengunjung yang berkunjung menyebutkan hal yang didapatkan di Interactive Art Museum Bali ialah foto dan pengalaman. Sebesar 3\% pengunjung yang berkunjung menyebutkan hal yang didapatkan di Interactive Art Museum Bali ialah pengetahuan pengalaman. Sebesar 5\% pengunjung yang berkunjung menyebutkan hal yang didapatkan di Interactive Art Museum Bali ialah pengetahuan dan foto. Dan sebesar 9\% pengunjung yang berkunjung menyebutkan hal yang didapatkan di Interactive Art Museum Bali ialah pengetahuan, pengalaman dan foto.

Dari hasil penjabaran diatas, selanjutnya dilakukan analisis korelasi antara variabel. Hasil dari analisis korelasi dapat dilihat pada tabel 4.3 dibawah ini:

Tabel 4.3 Analisis Korelasi

\begin{tabular}{cc}
\hline Analisis Korelasi & Instagram \\
\hline Foto & 0,668 \\
\hline Lukisan 3D & 0,627 \\
\hline Sumber : Hasil Penelitian, 2018
\end{tabular}

Sumber : Hasil Penelitian, 2018

Hasil analisis korelasi pada klasifikasi bagian ini menghasilkan angka 0,668 dan 0,627. Hal tersebut menunjukan bahwa media sosial Instagram memiliki hubungan yang sangat kuat dengan foto dan lukisan 3D karena angka koefisien dari hasil analisis korelasi tersebut diatas 0,5.

\section{Menurut Lingkungannya}

Dari klasifikasi bagian berdasarkan tanggapan pengunjung mengenai benda serta perkataan dari Interactive Art Museum Bali. Didapatkan Sebesar $8 \%$ pengunjung yang datang menyebutkan fasilitas di Interactive Art Museum Bali ialah rapi. Sebesar 4\% pengunjung yang datang mengyebutkan fasilitas di Interactive Art Museum Bali ialah sangat bersih. Sebesar 51\% pengunjung datang menyebutkan fasilitas di Interactive Art Museum Bali ialah sangat bagus.

Sementara itu, sebesar $7 \%$ pengunjung yang datang menyebutkan fasilitas di Interactive Art Museum Bali ialah bersih serta bagus. Sebesar $2 \%$ pengunjung yang datang mengatakan fasilitas di Interactive Art Museum Bali ialah rapi serta bagus. Sebesar 3\% pengunjung yang datang menyebutkan fasilitas di Interactive Art Museum Bali ialah bersih serta rapi. Dan sebesar $25 \%$ pengunjung yang datang menyebutkan fasilitas di Interactive Art Museum Bali ialah bersih, bagus serta rapi.

Selain mengenai fasilitas, pengunjung juga memiliki tanggapan terhadap pelayanan di Interactive Art Museum Bali. Didapatkan sebesar $15 \%$ pengunjung yang datang menyebutkan pelayanan di Interactive Art Museum Bali ialah sangat ramah. Sebesar $3 \%$ pengunjung yang datang menyebutkan pelayanan di Interactive Art Museum Bali ialah sangat sopan. Sementara itu, sebesar 40\% pengunjung yang datang menyebutakan pelayanan di Interactive Art Museum Bali ialah sangat baik.

Sementara itu, sebesar $7 \%$ pengunjung yang datang menyebutkan pelayanan di Interactive Art Museum Bali ialah sangat sopan serta sangat ramah. Sebesar $15 \%$ pengunjung yang datang menyebutkan pelayanan di Interactive Art Museum Bali ialah sangat ramah serta sangat baik. Dan sebesar $20 \%$ pengunjung yang datang menyebutkan bahwa pelayanan di Interactive Art Museum Bali ialah sangat sopan, sangat baik serta sangat ramah.

Dari hasil penjabaran diatas, selanjutnya dilakukan analisis korelasi antara variabel. Hasil dari analisis korelasi dapat dilihat pada tabel 4.4 dibawah ini:

Tabel 4.4 Analisis Korelasi

\begin{tabular}{ll}
\hline Analisis Korelasi & Instagram \\
\hline Baik & 0,585 \\
Bagus & 0,564 \\
\hline
\end{tabular}
Sumber : Hasil Penelitian, 2018

Hasil analisis korelasi pada klasifikasi bagian ini menghasilkan angka 0,585 dan 0,564. Hal tersebut menunjukan bahwa media sosial Instagram memiliki hubungan yang sangat kuat dengan baik dan bagus karena angka koefisien dari hasil analisis korelasi tersebut diatas 0,5.

Pengunjung yang datang ke Interactive Art Museum Bali malakukan kegiatan seperti berfoto didepan lukisan 3 dimensi serta berkeliling. Terlihat berdasarkan hasil dari analisis korelasinya sebesar 0,598. Salah satu kegiatan yang dapat membuat seseorang menjadi senang ialah berfoto. Karena dalam kegiatan berfoto seseorang diharuskan memilih latar fotonya. Didalam pemilihan latar, seseorang dapat mengalami pemulihan mental 
yang sangat baik karena dalam memilih latar tersebut harus sesuai dengan keinginannya.

Hubungan antara tanggapan pengunjung pada media sosial dengan pilihan koleksi di Interactive Art Museum Bali sangatlah relevan. Karena berdasarkan dari hasil analisis korelasi antara tanggapan yang ada di media sosial dengan pilihan koleksi bagi pengunjung memperoleh angka koefisien sebesar 0,668. Dari angka tersebut, sudah sangat sesuai dengan bagian dari pengertian konsep museum bahwa seseorang akan mengikuti keinginannya sendiri untuk memilih koleksi yang ada pada museum untuk menghibur diri sendiri didalam mencari kebahagiaan.

\section{KESIMPULAN DAN SARAN}

\subsection{Kesimpulan}

Menurut hasil penelitian yang dijelaskan di atas dapat disimpulkan sebagai berikut:

1. Media sosial Instagram, Twitter serta Facebook adalah media sosial yang digunakan pengunjung di Interactive Art Museum Bali. Tetapi media sosial yang paling banyak digunakan oleh pengunjung adalah Instagram dengan angka sebesar $37 \%$.

2. Pengaruh tanggapan di media sosial terhadap pilihan koleksi bagi pengunjung Interactive Art Museum Bali dapat dilihat berdasarkan dari konsep tanggapan yang digunakan yang memiliki 3 klasifikasi. Yang selanjutnya dari klasifikasi tersebut dianalisis dengan analisis korelasi. Menurut indra yang mengamati yang dianalisis korelasi antara lukisan 3D serta berfoto dengan Instagram pada klasifikasi bagian ini menghasilkan angka 0,598 dan 0,653 . Menurut terjadinya yang di analisis korelasi antara foto serta lukisan 3D dengan Instagram pada klasifikasi bagian ini menghasilkan angka 0,668 dan 0,627. Menurut lingkungannya yang di analisis korelasi baik serta bagus dengan Instagram pada klasifikasi bagian ini menghasilkan angka 0,585 dan 0,564.

\subsection{Saran}

Menurut hasil penelitian di atas, terdapat beberapa saran yaitu:

1. Memperbanyak akun selain akun yang sudah ada, jika pengelola menambahkan lagi maka informasi tentang Interactive Art
Museum Bali bisa tersebar luas serta dapat meningkatkan jumlah kunjungan pengunjung.

2. Memperbanyak lagi wahana seperti lukisan 3D, upside down, dan rumah hantu. Agar durasi waktu yang dimiliki pengunjung untuk berkeliling menjadi sangat lama. Serta pengunjung yang datang menerima kebahagiaan didalam mengelilingi Interactive Art Museum Bali.

\section{DAFTAR PUSTAKA}

Anonim. Undang-Undang Republik Indonesia No.10 Tahun 2009 Tentang Kepariwisataan.

Audifax. 2008. Re-search. Yogyakarta: Jalasutra.

Bruninghaus, Cornelia \& Knubel. 2004. Museum Education in The Context of Museum Functions, Running a Museum, A Practical Handbook, International Council of Museums.

Gallager, Robert G. 2008. Principles of Digital Communication. Amerika: Masssachusetts Institute of Technology.

Hutagalung, Lidia Uli Christiani Karmelia dan Saptono Nugroho. 2015. Efektivitas Program City Tour terhadap Peningkatan Jumlah Kunjungan Pengunjung di Museum Bali Denpasar. Jurnal Destinasi Pariwisata, 3 (1), 52-58.

Kotler, Philip dan Kevin Lane Keller. 2012. Marketing Management 14th ed. England : Pearson Education.

Marlianto, Ferry dkk. 2016. Pengaruh Media Sosial Terhadap Kreativitas dan Kepribadian Mahasiswa Pendidikan TIK IKIP PGRI Pontianak. Jurnal Pendidikan Informatika dan Sains, 5 (2), 212-226.

Purwidiantoro, Moch Hari dkk. 2016. Pengaruh Penggunaan Media Sosial terhadap Pengembangan Usaha Kecil Menengah (UKM). Jurnal EKA CIDA, 1 (1), 30-39.

Sarwono, Jonathan. 2006. Metode Penelitian Kuantitatif \& Kualitatif. Yogyakarta: Graha Ilmu.

Sujanto, Agus. 1996. Psikologi Perkembangan. Jakarta: PT. Rineka Cipta.

Surakhmad, Winarno. 1982. Pengantar interaksi belajar Mengajar, Dasar dan Teknik Metodologi Pengajaran. Bandung: Tarsito.

Susanto, Mikke. 2011. Diksi Rupa, Kumpulan dan Istilah Seni Rupa. Yogyakarta: Dicti Art Lab \& Djagat Art Shop.

Suwena, I Ketut dan I Gusti Ngurah Widyatmaja. 2010. Pengetahuan Dasar Ilmu Pariwisata. Denpasar: Udayana University Press.

Yoeti, Oka A. 1997. Perencanaan dan Pengembangan Pariwisata (cetakan pertama). Jakarta: PT. Pradnya Paramita. 